\title{
Research and Exploration on Some Problems in Software Testing Course in Colleges and Universities
}

\author{
Qiaoling Xie \\ School of Information Engineering, Xi'an University, 710065
}

Keyword: Software Testing; Courses; Computers; Universities

\begin{abstract}
With the development of economy and society, the demand for talents in computer information-related professions shows a multiples growth in our country. Software testing is accompanied by the production of software, which plays an irreplaceable role in the evaluation and shaping of computer software systems. As software systems become larger and more complex, the value of software testing is on the rise. Colleges and universities are the main places to cultivate information talents in our country. How to cultivate talents that meet the needs of the development of industry and have excellent knowledge is not only the need of social development, but also the inherent requirement of raising the level of education and teaching. On the other hand, there are still many problems in our country's software testing teaching, so college education reform of software testing courses is imperative.
\end{abstract}

\section{Introduction}

Software testing is a process that is used primarily to verify the correctness, safety, integrity and quality of software. In short, software testing is the process to find errors in a program and to compare the actual output value with the expected output value. Software testing is a set of well-designed test cases that operate on a defined set of conditions to detect errors, measure the quality of the software and make the necessary evaluations to see if they meet the initial design requirements.

Since the end of the last century, the software industry has developed rapidly and the size of single software has been on the increase. In some large software development process, software testing requires a lot of time and labor costs. In the process, some people questioned the role that software testing plays in software design. Some even think that it is unnecessary to continue to increase investment in software testing. However, practice and case have fully proved that software testing plays an irreplaceable role in software development and is the key link to ensure software robustness and reliability. According to incomplete statistics, about one-fifth of software-related graduates are employed in software-related occupations within five years of practicing. This figure shows in some ways the importance of software testing throughout the industry and at the same time reflects the social needs shortfalls in the software testing profession.

Under the current education system in our country, the main ways to cultivate software testing talents are still the major colleges and universities. After years of development and improvement of the software testing specialty in colleges and universities, the university has achieved fruitful results in teaching. However, there are still many unsatisfactory places. On the whole, there is still a big gap between software testing personnel training scale and skills and the actual market demand. Many students in school only learned the knowledge on books and they lack appropriate practical ability and the ability of innovation and development. The software testing classroom and teaching settings should be closely connected to the market and introduce advanced management concepts and teaching mode in the curriculum and teaching. Only in this way can we mold the team spirit of students in the background of quality education and enhance the ability of innovation and practice, so that the cultivation of talent and the market demand can be combined to promote and develop each other. 


\section{Teaching Status of Software Testing Course}

In general, software testing is a rapidly emerging new curriculum. It is an important course in computer software major, application major and information management major and is a compulsory course for advanced students in computer software development and testing and software testing. Its purpose is to make students familiar with the functions, methods, principles and norms of software testing on the basis of learning basic courses such as language design and software engineering so as to lay the corresponding foundation for future employment of students. Throughout the various colleges and universities software testing professional teaching, the main problems can be summarized as follows.

Course Plan and Progress Setting. In the curriculum planning and progress setting, at present most computer science major of colleges and universities begin to set up the software test course in the junior third semester. The main contents of course learning include the basic concepts, design techniques of black-and-white box design cases and the use of test tools, etc. During the period before graduation, the time for students to learn is too short. Many students can only get a general understanding of the course and do not have profound memory. Except for individuals who are hard-pressed or have the opportunity to participate in practice, the rest of the students are mainly impressed with the course in books. Teachers often talk about in general terms in the teaching of software testing. Besides, the distinction is not clear enough such as test technology, test management and test tools, so that students are not easy to grasp the key point. Coupled with the school-enterprise cooperation model is still in the exploratory stage and has not yet formed a mature mechanism, resulting in students can not promptly follow up for the latest test technology.

Single Teaching Method. As a branch of information professional, software testing courses should be combined with the most cutting-edge teaching methods. Unfortunately, the traditional method of writing on the blackboard or ppt is still the main means of software testing teaching. Teachers play a dominant role in classroom teaching and students play the role of listener most of the time. This boring, single and rigid teaching model is difficult to mobilize the enthusiasm of students learning, resulting in greatly reduced the efficiency of student learning. At present, the informatization construction of Chinese universities has made great development in many aspects, but some courses still lag behind in teaching methods. On the one hand, it is related to the long-term teaching habits of the vast majority of teachers, on the other hand, it also has a great relationship with the direction of informationization construction in colleges and universities. Changes in teaching methods is not only an old topic, but also a brand new proposition. How to be updated with the times on the teaching methods and means is a long-term issue that needs to be resolved by every educator.

Teaching Content Is Scattered and Teaching System Structure Is Incomplete. Software testing is throughout the software development. In actual teaching, the theory of software testing is relatively scattered and the fragmentation and simplification of all knowledge are more serious. Besides, the problem of out-of-synchronization between theoretical and practical testing processes is also prominent. All of this led to knowledge to be systematic and structured. At the same time, due to the teaching materials and the actual teaching arrangements and other issues, theories and methods have a long time delay, resulting in students can not digest and absorb what they have learned. In this teaching mode, theory can not form a complete and systematic framework in the minds of students and it is difficult for students to apply knowledge flexibly. At present, some schools are exploring ways to concentrate their teaching. In the early stage, they mainly study theories and then they digest and consolidate what they have learned through practice. The effect needs to be further observed, but this teaching method has its unique advantages for the construction of theoretical system.

Pay Much More Attention to Theory and Less Attention to Practice. This issue is a chronic problem in our education system. Many educators have discovered this problem very early. However, this issue has still plagued the education and teaching process for a long time. The reasons are both the assessment mechanism and the practical difficulties of the school. This is a systematic problem, so it is very difficult to achieve the desired result simply by changing one 
aspect of the problem. However, as the main implementer of education, it is our duty to change this shortcoming so that we can learn from it. Now the main focus of software testing teaching is still on the cultivation of students' software development ability, so the teaching requirements of software testing itself are often neglected. For example, many teachers talk about software testing itself when it comes to "software testing is for software development services." This sentence has no problem from the statement. However, software testing has its own irreplaceable uniqueness since it is an independent science. The requirements for practical ability of software testing are higher than software development in some ways. Contempt of practical ability is limited by the course materials. First, many school software testing teaching materials are obsolete and lack test cases. Second, since the software testing major belongs to emerging disciplines, many teachers do not have much experience in software testing teaching. Third, software development is still dominant in Chinese software industry. Many companies still maintain the old thinking of software testing and lack understanding of its importance.

Single Assessment Method. At present, the assessment of software testing is mainly based on papers, which has great drawbacks. Software testing courses has distinctive features. It attaches importance to practicality and applicability, so a simple paper test is difficult to fundamentally reflect the actual situation of student learning. In addition, the daily performance of students during the learning process is also crucial to the learning of this course. A simple assessment method can not reflect students' learning standards at all.

Prejudice in Thinking. The reason for putting this in the end is not that its importance should come to the end, but on the contrary, I think it is the most important aspect. The spread of emphasis on the development in domestic software industry has had a lot of negative impact on school education. First and foremost, many teachers and students see software testing as an adjunct tool and software design and development are paramount. This led to that teachers emphasize the theory and software programming in classroom teaching, while despise software testing. Students holding this view also tend to software design direction of their own life and career planning. They think that software testing is not as good as development and it is difficult to get due attention in the workplace. They see software testing as a repetitive task with little technical content and think that software development is the most advanced in the software industry. They believe that software testing is the end of software development and it just need to test when software development is finished. There are quite a few students hold on this view.

\section{Exploration on Optimization of Curriculum Teaching}

The author who is a teacher has deep feelings on the problems in the software testing course and also conducts a in-depth thinking. Here, he will share some experience gained from these teaching practices with others in the past years so as to achieve the purpose of exchange and cooperation. The author believes that software testing courses should focus on teaching optimization from the following aspects.

Optimize Course Settings. Software testing teaching should focus on cultivating students' practical ability and shaping students' ability to think and solve problems independently. Therefore, in the course of curriculum, teachers should rationally allocate the theory class hours and practice hours and increase the input for the practice class. The theory class requires the majority of teachers to prepare lessons carefully, try to sort out the basic theory and principle of the course and dig deeply the essence of the theory. The theory can not be explained simply by way of teaching, but should be project-driven, so that students can master knowledge gradually in the actual project.

In teaching, teachers also need to change the traditional teaching methods, so that students actively participate in the classroom teaching. Heuristic teaching methods should be adopted for students' learning problems so that students can think actively and lead them to solve problems independently. For some common problems, students should be organized to discuss, which can give students enough sense of participation.

Finally, on the choice of teaching materials, schools should make enough efforts to take account of the characteristics of school teaching and subject development and the times and try to select 
teaching materials that are close to student life and have distinctive characteristics.

Strengthen the Construction of Teaching Practice. Practical aspects has the core significance in the study of software testing. Only through practice, students can grasp the theory and method of software testing in the true sense and truly master the knowledge they have learned. In the classroom teaching, the author carefully designs a lot of experiments which includes basic processes and techniques of software testing. They are very representative. As software testing technology updates fast, teachers should fully and reasonably use the latest and most cutting-edge technological achievements in the experimental design and select the best test platform and program.

One of the most important aspects in practice is the way of cooperation between schools and enterprises. This approach has achieved the teaching expectation well from the perspective of promotion and application. Therefore, teachers should focus on the ways and means of cooperation between school and enterprises, so that students can enter the enterprise and let the enterprises enter the campus at the same time. In the school-enterprise cooperation mode, students not only have access to the most cutting-edge scientific and technological achievements and testing methods, but also timely adjust their career planning according to market demand. At the same time, contact with the business also allows students to understand the operating mechanism of modern enterprises, and they unconsciously adjust their own thinking to solve problems.

Create Specialized Teachers Team. The professionalization of teachers' team is also an important aspect of the overall improvement of curriculum quality. Many current practitioners are part-time teachers in software. To cultivate and create a team of professional teachers in software testing, schools must improve the teacher's admission mechanism. Secondly, schools must do a good job in cultivating and training teachers in the late stage and provide teachers with a platform for improving their skills. Schools and enterprises, schools and schools can carry out irregular exchange of personnel training programs. Besides, they should also encourage and introduce certain measures for the majority of teachers to learn each other.

Improve the Level of Information in Teaching Process. In the construction of school informatization, efforts should be made to improve the informatization level of education and teaching process. For example, schools can create multi-media communication and other systems for teachers and students in teaching, so that teachers can always feel the difficulties in students learning. Besides, students can also communicate with teachers or their classmates both in class and off class.

Develop Students' Sense of Teamwork. In recent years, software development can be said to be changing rapidly. Large-scale, modular and interconnection and so on have become the trend of software development. Besides, to develop students' awareness of teamwork has also become a trend in teaching. In teaching, teachers should tell students the teamwork and cooperation ideas, so that students can change their original idea of individual heroism and come into the new thinking of close teamwork.

\section{Acknowledgements}

Fund Project: This study is supported by 2017 Course Comprehensive Reform Project in Xi'an University(No. JG2017026).

\section{Reference}

[1] Z. H. Wang. Project Quality Management [M]. Beijing: Mechanical Industry Press, 2004.

[2] Z. W. Tang. Information System Development and Management [M]. Beijing: Science Press, 2008.

[3] H. Qin and Q. Yang. Software Quality Assurance and Testing [M]. Beijing: Tsinghua University Press, 2012 (1).

[4] W. Huang and M. Hong. Software Testing and Maintenance Fundamentals [M] Beijing: Mechanical Industry Press, 2011 (12).

[5] W. W. Chen. Software Testing [M]. Xi'an: Xi'an University of Electronic Science and 
Technology Press, 2011 (12).

[6] S. M. Zhu Edit. Software Testing Methods and Techniques, Tsinghua University Press, 2005.

[7] H. C. Zhang. Software Test Force System Analysis Architecture Based on Quality Attributes [J]. Microcomputer and Applications. 2011.

[8] G. F. Wu and Z. S. Wang. How to Effectively Improve the Software Quality in the Software Testing Stage [J]. Computer CD Software and Application. 2010.

[9] S. Qiu. Software Engineering Professional Software Testing Platform Construction Practice [J]. Modern Computer (Professional Edition). 2012

[10]Z. G. Li. Third-party Software System Acceptance Testing Practice [J]. Information Technology, $2010(1)$. 